\title{
Archaeal and methanogenic communities in the rice field under different fertilizer applications
}

\author{
YULI SITI FATMA, IMAN RUSMANA", ARIS TRI WAHYUDI, HAMIM \\ Department of Biology, Faculty of Mathematics and Natural Sciences, Institut Pertanian Bogor. Jl. Agatis, Dramaga Campus, Bogor 16680, \\ West Java, Indonesia. Tel./fax.: +62-251-8622833, `email: irusmana@ipb.ac.id.
}

Manuscript received: 5 August 2019. Revision accepted: 23 November 2019.

\begin{abstract}
Fatma YS, Rusmana I, Wahyudi AT, Hamim. 2019. Archaeal and methanogenic communities in the rice field under different fertilizer applications. Biodiversitas 20: 3667-3675. The archaeal community in the soil surrounding rice roots plays key roles in biogeochemical cycles. Methanogenic archaea contribute to $\mathrm{CH}_{4}$ production in the rice field and control $\mathrm{CH}_{4}$ emission rates; an important greenhouse gas significantly emitted from the rice field. Characteristic of archaeal and methanogenic community in Indonesian rice field has not been well documented. In this study, rice plants grown in the rice field were treated with two different fertilizer applications, i.e., $100 \%$ urea without biofertilizer $\left(250 \mathrm{~kg} \mathrm{ha}^{-1}\right)(\mathrm{B} 0)$, and $50 \%$ urea $\left(125 \mathrm{~kg} \mathrm{ha}^{-1}\right)$ with biofertilizer consisted of methanotrophic bacteria and $\mathrm{N}_{2} \mathrm{O}$-reducing bacteria (B1). Soil archaeal community of the two types of fertilization was characterized over the rice-growing period using 16S rRNA amplicon sequencing. The succession and dynamic of the archaeal population were detected in each of the two treatments before fertilizer application ( 0 days after transplanting [DAT]) until the rice generative phase (69 DAT). During the period, the archaeal soil community in both treatments was dominated by Crenarchaeota. The relative abundance of putative methanogens was higher in the B0 treatment than that of B1 treatment. Within the methanogenic community, Methanosarcinaceae and Methanomassiliicoccaceae which found as most dominant group in both treatments were presumably to be important contributors to $\mathrm{CH}_{4}$ emission. The application of 50\% urea with biofertilizer (B1) changed the structure of the archaeal and methanogenic community in the rice field compared to the application of $100 \%$ urea (B0).
\end{abstract}

Keywords: Amplicon sequencing, archaeal diversity, methane emission, methanogens, tropical soil

\section{INTRODUCTION}

Soils contribute as sources or sinks of many atmospheric trace gases (Conrad 1996). Diverse microbes inhabiting the rice field play essential roles in greenhouse gases $(\mathrm{GHG})$ emission, such as methane $\left(\mathrm{CH}_{4}\right)$. Rice plant released carbon compound through root exudates providing substrates for microbial growth and $\mathrm{CH}_{4}$ production (Aulakh et al. 2001a). $\mathrm{CH}_{4}$ formation is the final step of the anaerobic decomposition process of organic matter. Anaerobic condition in rice field provides a favorable condition for fermentative bacteria to decompose carbon complex compound, then methanogens consume the decomposition product, such as $\mathrm{H}_{2}$ and acetate, as an energy source and produce $\mathrm{CH}_{4}$ as a final product (Conrad 2007). $\mathrm{CH}_{4}$ emission is also influenced by $\mathrm{CH}_{4}$ oxidation, which mostly conducted in the aerobic zone and $\mathrm{CH}_{4}$ transportation through ebullition, diffusion, and aerenchyma of rice plants (Schütz et al. 1989; Mer and Roger 2001). Unfortunately, the application of urea fertilizer increased $\mathrm{CH}_{4}$ emission in the rice field (Fan et al. 2016; Liu et al. 2019). $\mathrm{CH}_{4}$ is the second major contributor to global warming after $\mathrm{CO}_{2}$ (IPCC 2007). Indonesia's rice cultivation in 2010 was included in the top five most contributor countries to GHG emission and was predicted to emit $\mathrm{CH}_{4}$ overtime continuously (USEPA 2013). The increase of GHG emissions would be triggered by the increase in rice demand along with the human population growth.
Archaea is ubiquitous microbes in the Earth's environment, such as soil, marine water, hydrothermal vent, sediment, and hypersaline environment. Archaea influences the biogeochemical cycles in various environmental habitat, including the greenhouse gas dynamic (Fan and Xing 2016). Methanogen is widely distributed in diverse archaeal taxa, including phylum Euryarchaeota. This group comprises several orders, including Methanomicrobiales, Methanosarcinales, Methanocellales (RC-I), Methanomicrobiales, Methanococcales, Methanopyrales, and Methanomassiliicoccales (Liu dan Whitman 2008; Borrel et al. 2013). According to the substrate types and methanogenic pathway, methanogens were divided into three groups, i.e., hydrogenotrophic methanogen using $\mathrm{H}_{2} / \mathrm{CO}_{2}$ or formate (in few members); methylotrophic methanogen using methyl compounds, such as methanol, methylamine, and methyl sulfide; and acetilastic methanogen using acetate (Liu and Whitman 2008). A previous study reported that the methanogenic community structure in the rice field was influenced by urea addition (Liu et al. 2019) and desiccation (Reim et al. 2017).

$\mathrm{CH}_{4}$ mitigation could be achieved by methanogens suppression and methanotrophs stimulation (Fazli et al. 2013). In the rice agriculture sector, innovative strategies are needed to be developed to improve rice production and reduce $\mathrm{CH}_{4}$ emission. The application of the reduced amount of urea and biofertilizer containing methaneoxidizing bacteria and $\mathrm{N}_{2}$-reducing bacteria has been 
reported to lead a positive impact not only in rice plant growth enhancement but also on the decrease in $\mathrm{CH}_{4}$ and $\mathrm{N}_{2} \mathrm{O}$ emissions (Sukmawati et al. 2015; Fatma 2019). However, the archaeal community in the rice field, apply ing with $50 \%$ urea and biofertilizer, and $100 \%$ urea application (Indonesia standard practice) carried out in this study is still unknown. Recognization of the characteristic of archaeal and methanogen communities in rice field ecosystems could give a better understanding of microbial community function involved in $\mathrm{CH}_{4}$ emission. The archaeal community structure was investigated using $16 \mathrm{~S}$ rRNA gene amplicon sequencing through sequencing by synthesis technique. We have interested in the diversity and composition of Archaea between the two fertilizer applications during rice vegetative and generative phases.

\section{MATERIALS AND METHODS}

\section{Materials}

Biofertilizer used in this study consists of methanotrophic bacteria (Methylocystis rosea BGM1, Methylocystis parvus BGM3, Methylococcus capulatus BGM9, and Methylobacter sp. SKM14) and $\mathrm{N}_{2} \mathrm{O}$-reducing bacteria (Ochrobactrum anthropi BL2) (Rusmana and Akhdiya 2009). BGM1, BGM3, and BGM9 were isolated from rice field soil in Bogor, West Java, Indonesia. SKM14 was isolated from rice field soil in Sukabumi, West Java, Indonesia (Rusmana and Akhdiya 2009). BL2 was isolated from rice field soil in Tangerang, Banten, Indonesia (Setyaningsih et al. 2010).

\section{Study area}

The field experiment was conducted at Tegal, Central Java, Indonesia $\left(7^{\circ} 02^{\prime} 44.8^{\prime \prime} \mathrm{S}, 109^{\circ} 08^{\prime} 16.6^{\prime \prime} \mathrm{E}\right)$. Rice field soil was categorized as silt loam soil comprised of $23.31 \%$ sand, $75.98 \%$ silt, and $0.71 \%$ clay with $\mathrm{pH}$ 6.55. Soil carbon and nitrogen contents were $3.30 \%$ and $0.12 \%$, respectively (Fatma 2019).

\section{Rice field experiment}

Rice plants were grown in the rice field and treated with two different fertilizer applications, i.e., 1) $100 \%$ urea (250 $\mathrm{kg} \mathrm{ha}^{-1}$ ) without biofertilizer (B0); 2) $50 \%$ urea (125 kg ha $\left.{ }^{1}\right)$ with biofertilizer consisted of methanotrophic bacteria and $\mathrm{N}_{2} \mathrm{O}$-reducing bacteria (B1). B0 and B1 were performed at the separated block with a total area of 1,400 $\mathrm{m}^{2}$ and $1,500 \mathrm{~m}^{2}$. Each block was divided into three plots. The 25-day-old seedlings of Indonesian rice cultivar 'Membramo' were used in the two treatments (three plants per hill). In B0 treatment, rice seedlings were transplanted with a spacing of $20 \mathrm{~cm} \times 20 \mathrm{~cm}$, then applied with $100 \%$ urea in 15 days after transplanting (DAT). For B1, the roots of rice seedlings were soaked in biofertilizer containing bacterial cells with the total number was $10^{8}$ cells $\mathrm{mL}^{-1}$ for approximately 15 minutes, then transplanted in the rice fields with a spacing of $20 \mathrm{~cm} \times 20 \mathrm{~cm}$ and applied with $50 \%$ urea at 15 DAT.

\section{Soil sample collection and microbial DNA extraction}

Soil samples surrounding rice roots in each treatment were collected three times representing the plant age or the crucial phase of rice plant growth, i.e., before fertilizer application (0 DAT), vegetative stage of rice (36 DAT), and generative stage of rice (69 DAT). Soil samples were randomly collected in triplicates in each treatment. Triplicate soil samples with the same amount ratio from the same treatment were mixed to form a homogenous composite soil representing the overall microbial communities. Totally of six soil samples (2 treatments x 3 sampling time) were investigated for further study. DNA of soil was extracted using ZymoBIOMICS DNA Mini Kit (Zymo Research, Irvine, CA, USA) according to the manufacturer's instructions. The quality and quantity of DNA were measured by NanoDrop (NanoDrop Technologies, Wilmington, US) and electrophoresis on agarose gel $2 \%$.

\section{Archaeal 16S rRNA gene preparation and sequencing}

16S rRNA gene amplicon was prepared through the two-step PCR protocol by Illumina. Before running the protocol, a full length of the archaeal 16S rRNA gene was generated using primer set 21F-958R (Delong 1992). PCR reaction mixture was prepared in $25 \mu \mathrm{L}$ using Q5 Hot Start High Fidelity PCR 2X Master Mix (New England Biolabs, Ipswich, MA, US), consisted of $12.5 \mu \mathrm{L}$ of Q5 HighFidelity $2 \mathrm{x}$ Master Mix, $1.25 \mu \mathrm{L}$ each of $10 \mu \mathrm{M}$ forward and reverse primers, $5 \mu \mathrm{L}$ of the template DNA, and $5 \mu \mathrm{L}$ of nuclease-free water. $\mathrm{PCR}$ reaction was performed in 30 cycles of $94^{\circ} \mathrm{C}$ for $45 \mathrm{sec}, 55^{\circ} \mathrm{C}$ for $60 \mathrm{sec}$, and $72^{\circ} \mathrm{C}$ for 90 sec. In the first PCR stage, the V4 region of the archaeal 16S rRNA gene was amplified using primer set Parch519fArch915r (Coolen et al. 2004) added with the Illumina overhang adapter sequences. The initial PCR reaction mixture in a total volume of $25 \mu \mathrm{L}$ consisted of $12.5 \mu \mathrm{L}$ of Q5 High-Fidelity 2x Master Mix, $1.25 \mu \mathrm{L}$ of each $10 \mu \mathrm{M}$ forward and reverse primers, $5 \mu \mathrm{L}$ of the template DNA, and $5 \mu \mathrm{L}$ of nuclease-free water. The cycling parameter used in the first $\mathrm{PCR}$ reaction were 1 cycle at $98^{\circ} \mathrm{C}$ for 30 sec, 30 cycles of $98^{\circ} \mathrm{C}$ for $10 \mathrm{sec}, 71^{\circ} \mathrm{C}$ for $30 \mathrm{sec}, 72^{\circ} \mathrm{C}$ for $30 \mathrm{sec}$, and $1 \mathrm{cycle}$ at $72^{\circ} \mathrm{C}$ for $2 \mathrm{~min}$. Quantity and quality of PCR products were measured by Agilent 4200 TapeStation System (Agilent Technologies, Inc., Santa Clara, CA, USA), Helixyte ${ }^{\mathrm{TM}}$ Green dsDNA Quantifying reagent (AAT Bioquest Inc, CA, USA), and Nanodrop (Thermo Scientific, Wilmington, DE, US). Sample with DNA fragment in approximately 400 bp was chosen for further step. The PCR products obtained were purified by the Qiagen Gel Extraction Kit (Qiagen, Hilden, DE). In the second PCR stage, PCR was performed to dual indices addition using the Nextera XT DNA Library Prep Kit (Illumina, US). PCR reaction mixture was prepared in 50 $\mu \mathrm{L}$ comprised of $25 \mu \mathrm{L}$ of Q5 High-Fidelity $2 \mathrm{x}$ Master Mix, $5 \mu \mathrm{L}$ of each Nextera XT i7 and Nextera XT i5 indices, $5 \mu \mathrm{L}$ of PCR product from the first PCR stage, and $10 \mu \mathrm{L}$ of nuclease-free water. The reaction starts with an initial denaturation at $98^{\circ} \mathrm{C}$ for $3 \mathrm{~min}, 8$ cycles of $98^{\circ} \mathrm{C}$ for $30 \mathrm{sec}, 55^{\circ} \mathrm{C}$ for $30 \mathrm{sec}$, and $72^{\circ} \mathrm{C}$ for $30 \mathrm{sec}$, a final extension at $72^{\circ} \mathrm{C}$ for $5 \mathrm{~min}$. Finally, the amplicon with 
Illumina adapter and indices were sequenced using the Illumina MiSeq platform (Illumina, Inc., San Diego, CA, USA) according to customer service by Axil Scientific, Singapore.

\section{Analysis of sequences data}

The $250 \mathrm{bp}$ paired-end reads were obtained from Illumina-based sequencing. Paired-end reads were set according to their unique barcode, then merged using FLASH v1.2.7 (Magoč and Salzberg 2011). Paired-end reads merging was performed when at least some reads overlap to the read from the opposite end of the same DNA fragment. The splicing sequences were named as raw reads. The quality of the raw reads was filtered to obtain the highquality reads under specific filtering condition based on the QIIME v1.7.0 (Caporaso et al. 2010; Bokulich et al. 2013). The high-quality reads were compared to the GOLD database using UCHIME algorithm to detect chimera sequence. Then, chimeric sequences were removed to obtain effective tags (Edgar et al. 2011). Then, UCLUST was used for operational taxonomic unit (OTU) clustering with $\geq$ a $97 \%$ cut-off. Sequences in the same OTU were screened to obtain a representative sequence. The representative sequence was annotated against the GreenGene database (DeSantis et al. 2006) to get taxonomic information according to the RDP classifier algorithm v2.2 (Wang et al. 2007). OTU abundance information was normalized based on the sample with the fewest sequence number. Normalized data were subsequently used for determining alpha and beta diversity. Alpha diversity was calculated using QIIME v1.7.0 and displayed using $\mathrm{R}$ software v2.15.3. Beta diversity was analyzed according to the UniFrac method. Clustering analysis between samples was carried out by UPGMA based on weighted UniFrac distance. Analysis of UPGMA was performed using QIIME v1.7.0. Pearson correlation analysis was performed to identify the correlation between the relative abundance of archaeal class and plant age.

Additionally, the analysis of putative methanogens was conducted by collecting the archaeal taxa known as $\mathrm{CH}_{4}$ producer. Then, the relative abundance of the group was measured to obtain the relative abundance of methanogens in each sample. Putative methanogens were integrated with $\mathrm{CH}_{4}$ emission rates at both treatments during the rice vegetative and generative phase (Fatma 2019).

\section{RESULTS AND DISCUSSION}

\section{Variations of archaeal diversity}

The archaeal community structure based on the $16 \mathrm{~S}$ rRNA gene was investigated three times $(0,36$, and 69 DAT) for each treatment. We obtained 2,577,911 raw reads from six soil samples. After quality filtering (short sequence reads and low-quality reads removal), chimera, and singleton removal, we retrieved 1,996,532 effective reads. Alpha diversity was shown in observed species, richness estimator (Chao1 and ACE), and diversity index (Shannon, Simpson's, and equitability index) (Table 1). We found that Chao1, ACE, Shannon, and Simpson of the archaeal sequence in B1 were higher than that of B0 before fertilizer treatments and throughout the rice growth period. Shannon and Simpson's index indicated that Archaea were highly diverse in each of the two treatments. The number of OTUs and alpha diversity in each treatment increased from 0 to 69 DAT. In B0 treatment, Chaol and ACE increased along with the rice-growing phase, yet the number of observed species, Simpson and Shannon index, decreased. Meanwhile, alpha diversity in B1 gradually increased during the sampling time. Rarefaction curve of archaeal sequences nearly reached saturation level for all samples indicating that archaeal communities in each sample were very diverse and required additional samples to obtain a higher sequencing depth.

OTUs obtained from rice field soil was visualized in the Venn diagram (Figure 2). The diagram shows archaeal succession in each treatment along the rice-growing period. Specific OTU at a certain time $(0,36$, or 69 DAT) in B0 treatment was relatively higher than that of $\mathrm{B} 1$, that is $9.5 \%$ and $7.1 \%$ at 0 DAT; $14.0 \%$ and $5.1 \%$ at 36 DAT; and $18.1 \%$ and $6.8 \%$ at 69 DAT, respectively. In contrast, OTUs commonly found in all sampling time had a higher percentage at B1 $(45 \%)$ compared to B0 $(21.1 \%)$.

Table 1. Summary of the archaeal sequence obtained from rice field soil

\begin{tabular}{|c|c|c|c|c|c|c|c|c|c|}
\hline \multirow[b]{2}{*}{ Samples } & \multicolumn{3}{|c|}{ Sequence number } & \multicolumn{6}{|c|}{ Alpha diversity } \\
\hline & $\begin{array}{l}\text { Raw } \\
\text { reads }\end{array}$ & $\begin{array}{l}\text { Effective } \\
\text { reads }\end{array}$ & $\begin{array}{l}\text { Number } \\
\text { of OTUs }\end{array}$ & $\begin{array}{l}\text { Observed } \\
\text { species }\end{array}$ & $\begin{array}{c}\text { Shannon } \\
\left(H^{\prime}\right)\end{array}$ & $\begin{array}{l}\text { Simpson } \\
\text { (D) }\end{array}$ & $\begin{array}{l}\text { Shannon } \\
\text { equitability } \\
\text { (EH) }\end{array}$ & Chao1 & ACE \\
\hline \multicolumn{10}{|l|}{ B0 treatment } \\
\hline $\mathrm{OB} 0$ & 107,618 & 78,646 & 12,184 & 9,293 & 6.926 & 0.993 & 0.736 & 11,839 & 12,453 \\
\hline $36 \mathrm{~B} 0$ & 466,168 & 388,188 & 19,249 & 8,770 & 6.165 & 0.980 & 0.625 & 15,039 & 16,020 \\
\hline $69 \mathrm{~B} 0$ & 478,479 & 390,271 & 21,036 & 9,118 & 6.143 & 0.982 & 0.617 & 16,343 & 17,868 \\
\hline \multicolumn{10}{|c|}{ B1 treatment } \\
\hline 0B1 & 546,659 & 415,958 & 31,243 & 13,145 & 7.187 & 0.994 & 0.694 & 22,835 & 25,260 \\
\hline 36B1 & 424,796 & 316136 & 29,952 & 13,898 & 7.320 & 0.995 & 0.710 & 23,808 & 26,130 \\
\hline 69B1 & 554,191 & 407,333 & 32,381 & 14,066 & 7.394 & 0.996 & 0.712 & 24,272 & 27,147 \\
\hline
\end{tabular}

Note: 0B0: 100\% urea at 0 DAT, 0B1: 50\% urea with biofertilizer 0 DAT, 36B0: 100\% urea at 36 DAT, 36B1: 50\% urea with biofertilizer at 36 DAT, 69B0: 100\% urea at 69 DAT, 69B1: 50\% urea with biofertilizer at 69 DAT 


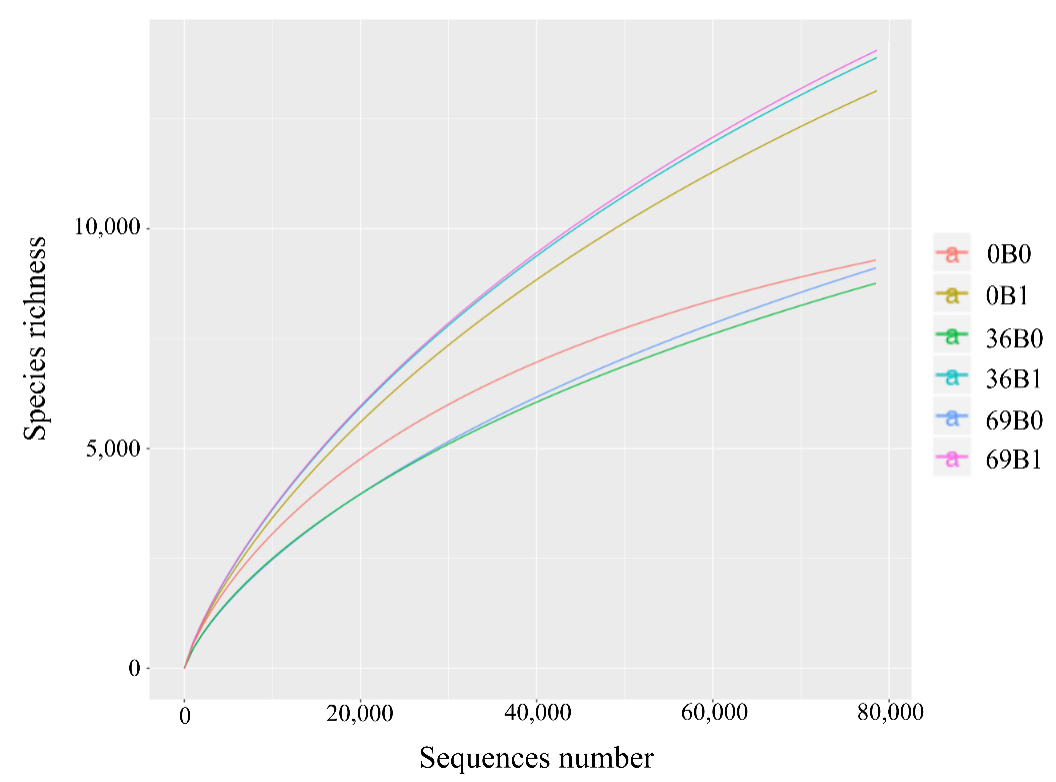

Figure 1. Rarefaction curves of archaeal OTUs at 97\% similarity cut-off for each sample

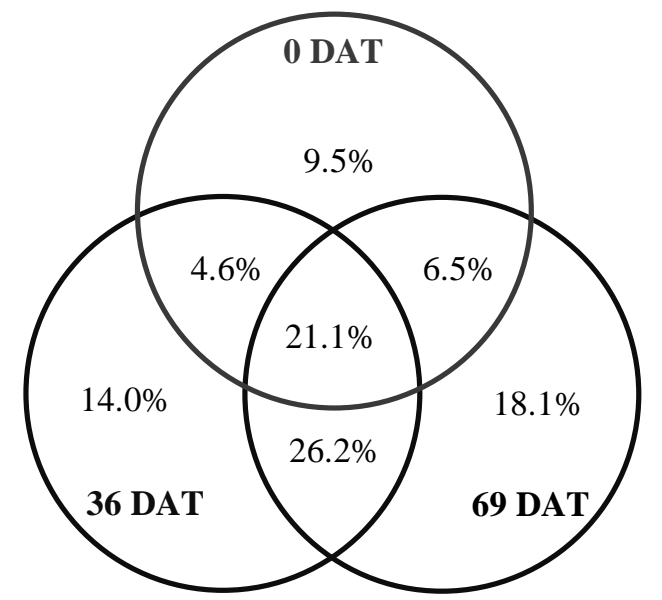

A

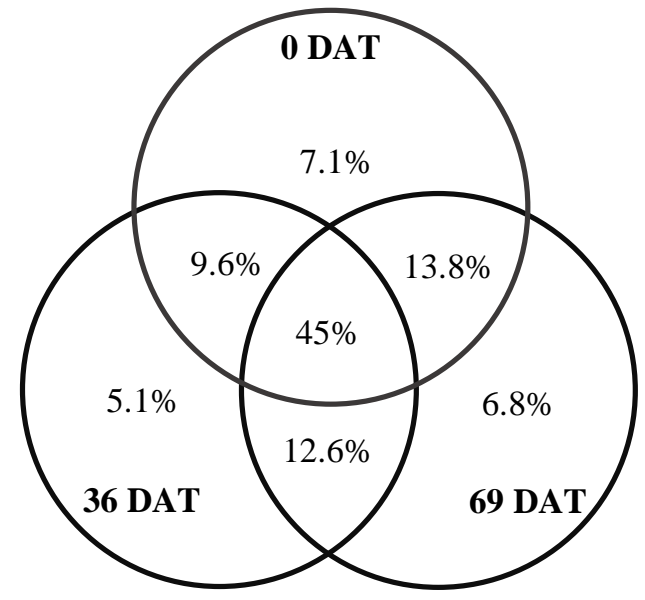

B

Figure 2. Venn diagram of the archaeal community from B0 (A) and B1 (B) treatment

\section{Taxonomic composition of total Archaea}

The taxonomic assignment of archaeal sequences was conducted against the Greengene database. Of all OTUs in each sample, archaeal OTUs were successfully classified into phylum and class levels with a high percentage (97$98.5 \%$, respectively). Unfortunately, the percentage of classified OTU dramatically declined in ordo, family, and genus level $(68.5-78.2 \%, 39.9-49 \%$, and $18.9-33.6 \%$, respectively).

The result of the taxonomic assignment is only shown in the phylum and class level (Figure 3). At the phylum level, Crenarchaeota (ranging from $71.6 \%$ to $77.2 \%$ ) was the most dominant group followed by Euryarchaeota (ranging from $21.2 \%$ to $25.6 \%$ ) in both treatments during a rice-growing period (Figure 3A). At the class level, the results showed that MCG (Miscellaneous Crenarchaeotic Group, renamed as Bathyarchaeota, belonging to Crenarchaeota) (47.4-50.6\%) was the most abundant in all samples, followed by Thaumarchaeota (14.8-28.1\%), Thermoplasmata $(5.2-16.5 \%)$, Methanomicrobia (7.5$15.4 \%$ ), MBGA (Marine Benthic Group A, 0.5-2.9\%), Thermoprotei (0.1-2.4\%), Methanobacteria (0.3-1.6\%), MBGB (Marine Benthic Group B, 0.1-0.4\%), and DSEG (Deep Sea Euryarchaeotic Group, $\leq 0.3 \%$ ) (Figure 3B). Pearson's correlation coefficients between the major archaeal group and plant age were calculated at the class level (Table 2). The archaeal community in class level of taxonomy was in relatively little change at both treatments along the rice cultivation period. In B0, plant age was negatively correlated with MBGA and Methanobacteria (r $<-0.8$ ). Meanwhile, in B1, plant age was positively correlated with MCG, Thermoplasmata, and MBGA ( $\mathrm{r}$ > 0.8 ), but negatively correlated with Thaumarchaeota, Methanomicrobia, and MBGB $(r<0.8)$. DSEG in B1 treatment was stable from 0 to 69 DAT. 

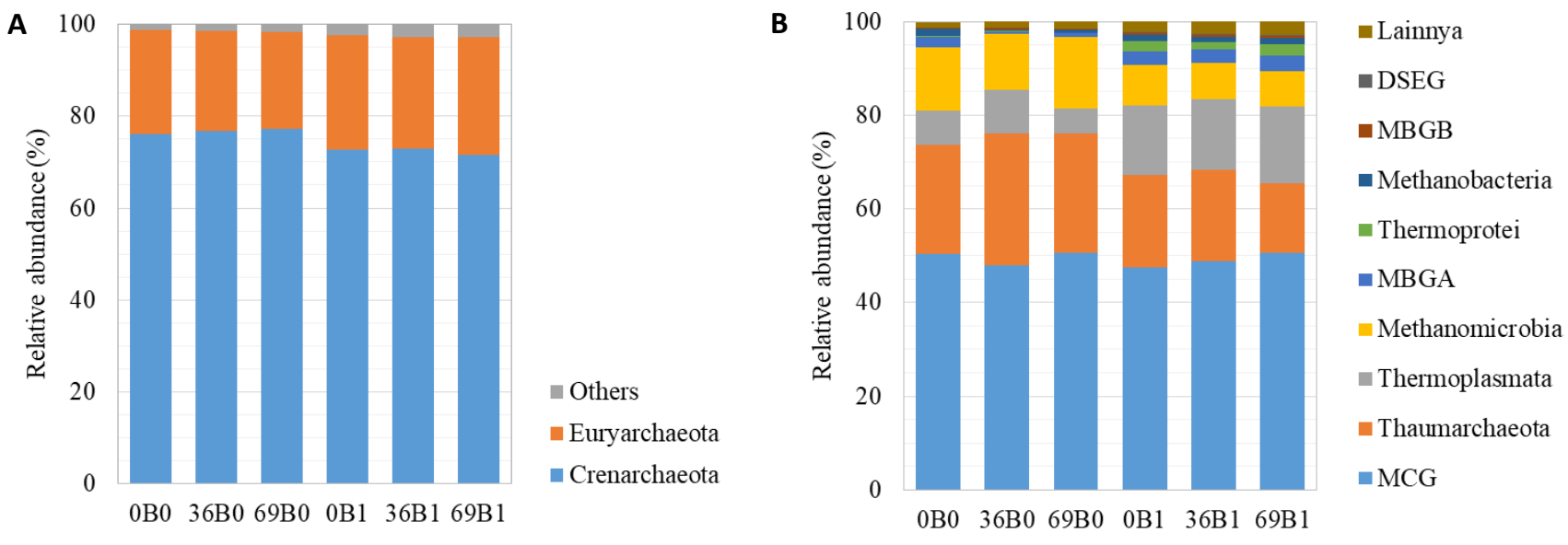

Figure 3. The archaeal composition showed the dynamic of the top ten dominant Archaea in the rice field treated by two different fertilizer treatments during the rice growth period. The 16S rRNA gene sequences were classified at the phylum (A) and class (B) level of the taxonomy. The colored bars represent the relative abundance of gene copies corresponding to the archaeal group present in the samples. Abbreviations: DSEG: Deep Sea Euryarchaeotic Group; MBGB: Marine Benthic Group B; MBGA: Marine Benthic Group A; MCG: Miscellaneous Crenarchaeotic Group.

Table 2. Correlation between the relative abundance of Archaea and plant age for high abundance class in each treatment calculated by Pearson's correlation

\begin{tabular}{lccccc}
\hline \multirow{2}{*}{ Class } & \multicolumn{2}{c}{$\mathbf{1 0 0 \%}$ urea $(\mathbf{B 0})$} & & \multicolumn{2}{c}{$\mathbf{5 0 \%}$ urea + biofertilizer (B1) } \\
\cline { 2 - 3 } \cline { 5 - 6 } & $\mathbf{r}$ & $\boldsymbol{P}$ & 0.972 & $\mathbf{P}$ & 0.062 \\
MCG & 0.044 & 0.511 & 0.658 & $\mathbf{0 . 9 9 5}$ & 0.304 \\
Thaumarchaeota & -0.502 & 0.665 & $\mathbf{- 0 . 8 8 8}$ & 0.214 \\
Thermoplasmata & 0.521 & 0.651 & $\mathbf{0 . 9 4 4}$ & 0.163 \\
Methanomicrobia & $\mathbf{- 0 . 8 2 2}$ & 0.386 & $\mathbf{- 0 . 9 6 7}$ & 0.349 \\
MBGA & -0.025 & 0.984 & $\mathbf{0 . 8 5 3}$ & 0.862 \\
Thermoprotei & $\mathbf{- 0 . 8 0 1}$ & 0.409 & 0.216 & 0.804 \\
Methanobacteria & 0.522 & 0.651 & 0.409 & 0.317 \\
MBGB & 0.522 & 0.651 & $\mathbf{- 0 . 8 7 8}$ & - \\
DSEG & & 0.000 & \\
\hline
\end{tabular}

Note: Bold numbers indicates a positive correlation $(r>0.8)$ or a negative correlation $(r<-0.8)$

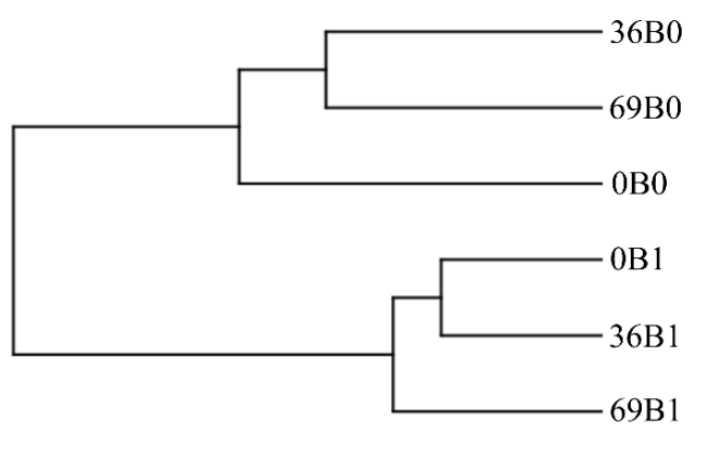

Figure 4. UPGMA based on weighted UniFrac distance matrix for archaeal communities in all samples

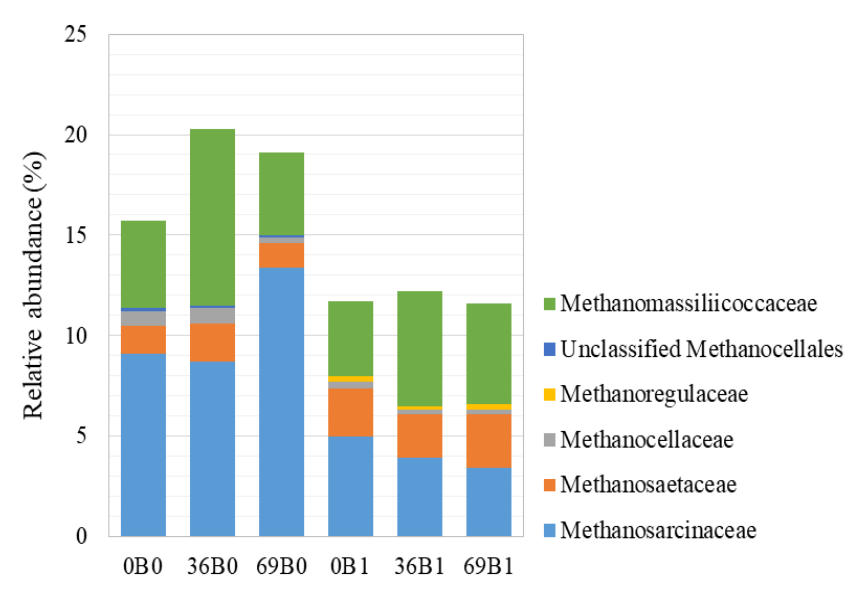

Figure 5. The relative abundance of putative methanogens at the family level of taxonomy in two different fertilizer treatments along rice growing period 
UPGMA was constructed to interpret the archaeal community structure between samples. The archaeal composition was clustered by the treatments, i.e., B0 and B1 (Figure 4). In the B0 treatment, the archaeal community in the rice vegetative phase (36B0) was similar to the generative phase (69B0). In contrast, in the B1 treatment, the archaeal community in 0 and 36 DAT (0B1 and 36B1) had a high similarity.

\section{The relative abundance of putative methanogens}

To obtain the relative abundance of putative methanogens, we collected OTUs at family level belonging to class Methanomicrobia and Methanobacteria, and member of Methanomassiliicoccaceae (class Thermoplasmata) which successfully detected in this present study. Putative methanogens were present in approximately $11.6-20.3 \%$ of the total archaeal sequencing reads in all samples (Figure 5). A higher proportion of putative methanogens was detected in B0 (15.7-20.3\%) compared to B1 (11.6-12.2\%) over the rice-growing period. At the two treatments, the highest proportion of putative methanogens was detected at 36 DAT. B0 treatment was dominated by Methanosarcinaceae at 0,36 , and 69 DAT (9.1, 8.7, and $13.4 \%$, respectively). Methanomassiliicoccaceae was also the most dominant in $\mathrm{B} 0$ treatment at the rice vegetative phase $(8.8 \%)$. In B1 treatment, Methanosarcinaceae was only dominant at 0 DAT $(5 \%)$, while Methanomassiliicoccaceae dominated the methanogen community at 36 and 69 DAT (5.7 and 5\%, respectively). Unclassified Methanocellales and Methanoregulaceae were only detected in B0 and B1 treatment, respectively. At the genus level (data were not shown), Methanosarcina was the most common group in both treatments by $8.7-13.4 \%$ in B0 and $3.4-5 \%$ in B1 treatment.

\section{Discussion \\ Archaeal diversity and composition in the rice field soil}

The diversity and composition of Archaea in all samples were investigated by Illumina sequencing analysis of the 16S rRNA gene. Analysis of alpha diversity showed that the Archaea in $\mathrm{B} 1$ was more diverse than that of $\mathrm{B} 0$ treatment before fertilizer application (0 DAT) and along rice growing period (36 and 69 DAT) (Table 1; Figure 1). In B0 treatment, the archaeal diversity was slightly declined over the rice-growing stage, which was possibly due to the decrease in root exudates. They also might not well adapted to the reduction of water level during the rice generative stage.

Meanwhile, the archaeal diversity in B1 was relatively increased from 0 to 69 DAT (Table 1). The archaeal community in B1 were presumably highly adapted to anoxic and oxic conditions and the change in environmental condition in the rice field. Their substrates were supplied by root exudates, where the rice plant growth in B1 was higher compared to B0 (Fatma 2019). Microbial community in the rhizosphere was influenced by rhizodeposition during plant growth, reaching the maximum number at the rice reproductive stage (Aulakh et al. 2001b). During rice growth, the succession of the archaeal community differed between the two treatments (Figure 2). A higher number of OTUs commonly found in all sampling time in B1 treatment indicated that these archaeal OTUs are more adaptable to the fluctuation of environmental conditions. B1 treatment supports the survival of certain OTUs during the rice-growing period. Several studies showed that archaeal communities are relatively stable and resistant to environmental perturbation, such as drainage (Itoh et al. 2013; Breidenbach and Conrad 2015).

According to the taxonomic assignment, unclassified OTUs were observed in high proportions. It indicated that the archaeal community in the rice field soil was highly diverse. It was observed that Crenarchaeota was the most dominant archaeal phylum (Figure 3.A), which is in agreement with a study conducted by Ahn et al. (2012) in Korea rice field soil. In contrast to our observations, Euryarchaeota (dominated by Methanomicrobia) were most frequently detected in rice soil under both waterlogged and drained conditions (Itoh et al. 2013; Lee et al. 2014). We detected MCG, Thaumarchaeota, Thermoprotei, MBGA, and MBGB within the Crenarchaeota phylum of all dominant classes (Figure 3.B). MCG (Bathyarchaeota) was found as the most abundant group in the rice field soil, which is consistent with some prior findings (Lee et al. 2014; Breidenbach and Conrad 2015). MCG was most commonly found in the topsoil layer of rice field at a depth of 0-5 cm (Vaksmaa et al. 2017), and account for $42 \%$ in rice field subsoils (Bai et al. 2017). MCG has been proposed as an anaerobic heterotroph, which might have metabolic activity in complex organic decomposition, such as protein and aromatic compounds (Lloyd et al. 2013). MCG may highly contribute to the degradation of organic compounds that supply nutrients for other microbes. Their potential in $\mathrm{CH}_{4}$ cycles needs further investigation (Evans et al. 2015). Thaumarchaeota was the second abundant class in this study. This group was also frequently found in aerated soil as ammonia oxidizers (Nicol et al. 2003) and supposed to be involved in $\mathrm{N}_{2} \mathrm{O}$ emission. Thermoprotei is highly distributed across marine and freshwater ecosystems, which was considered as hydrocarbon degraders (Gründger et al. 2015). MBGA, MBGB, MCG, and Thaumarchaeota, were major groups in the deep subsurface environment, such as sediment in the South China Sea (Wang et al. 2013). These archaeal roles in the environments need to be further observed. MBGB has been proposed as a heterotrophic microorganism that uses organic matter under anaerobic conditions (Biddle et al. 2006). In the phylum Euryarchaeota, we detected the presence of Thermoplasmata, Methanomicrobia, Methanobacteria, and DSEG (Figure 3.B). Thermoplasmata and Methanomicrobia were prominent in the Euryarchaeota community, as reported by Ahn et al. (2012). Thermoplasmata, such as Thermoplasmatales might involve in complex organic compounds degradation (Fan and Xing 2016) and may play a key role in $\mathrm{CH}_{4}$ emission, including Methanomassiliicoccales (Borrel et al. 2014). 
Methanomicrobia and Methanobacteria have been known as $\mathrm{CH}_{4}$ producers (Liu and Whitman 2008).

Changes in a few archaeal classes were observed in each treatment, but these changes were statistically not significant (Table 2). Population dynamics were possibly caused by changes in nutrient availability through fertilizer application and root exudation, and environmental factors during the rice cultivation period. Different fertilizer treatments may influence environmental characteristics with distinct effects, including plant and microbes response and their interactions. According to weighted Unifrac distance, the archaeal community was grouped into two clusters (B0 and B1) corresponding to the treatments (Figure 4), suggesting that the archaeal community was specified based on the treatments. Fertilizer treatment, rather than plant growth, has more effect on the bacterial community in the rice field soil.

\section{The relative abundance of putative methanogens over the rice-growing period}

The relative abundance of putative methanogens observed in this study (11.6-20.3\%, Figure 5) was lower than that of reported in a previous study $(68.3-86.6 \%)$ in the Korea rice field soil during rice cultivation period (Lee et al. 2014). A higher proportion of putative methanogens was observed in B0 (12.2-15.9\%) than that of B1 treatment (8.9-10\%), in which B0 showed a higher $\mathrm{CH}_{4}$ emission rate at the rice vegetative and generative phases (Fatma 2019). In $50 \%$ urea and biofertilizer treatment (B1), Methanobacteria decreased during the rice growth stage (Table 2), indicating that this group was not well adapted. At the vegetative rice phase, putative methanogens reached the highest proportion in both treatments (Figure 5). During this phase, rice tillers are actively formed, and some tillers die, causing an increase in the supply of organic compounds for methanogens growth. The dynamics of community structure and metabolic activity of methanogens influence $\mathrm{CH}_{4}$ emission (Watanabe et al. 2010). Inoculation of methanotrophs and $\mathrm{N}_{2} \mathrm{O}$-reducing bacteria in the rice field might stimulate interactions with resident soil microbes, which shifting microbial composition, including methanogens. Application of 50\% urea with biofertilizer (B1) causes the relative abundance of methanogens to decline in comparison to the application of $100 \%$ urea (B0) (Figure 5). Then, the shifting of methanogenic composition was likely to influence methane emission. The mechanism of shifting archaeal and methanogenic composition is still unclear and needs further analysis. According to Trabelsi and Mhamdi (2013), microbial inoculation to the soil could stimulate or suppress the indigenous microbes in the environment.

The results of our study showed that Methanosarcinaceace and Methanomassiliicoccaceae were the most prevalent group in both treatments over the rice-growing period (Figure 5). These methanogens might be major contributors for $\mathrm{CH}_{4}$ production in both treatments. Methanosarcina, the member of Methanosarcinaceae, was present during the rice-growing season, this is also reported in a previous study (Singh et al. 2012). Methanosarcina- ceace was commonly found in B0 treatment. This family has been reported as a common methanogen in rice field soil (Lueders and Friedrich 2000; Wang et al. 2010; Watanabe et al. 2010; Singh et al. 2012; as reviewed by Fazli et al. 2013 and Yuan et al. 2018). Interestingly, Methanomassiliicoccaceae was rarely detected in the rice field soil but was frequently detected in the treatment of $50 \%$ urea and biofertilizer application (B1) at the rice vegetative and generative phases. Reim et al. (2017) reported that the relative abundance of Methanosarcinaceace increased after desiccation and rewetting of the rice field. A previous report by Lee et al. (2014) showed that members of the class Methanomicrobia (Euryarchaeota) was the predominant archaeal in rice soil during the entire rice growth period. Some methanogens, including Methanocella, Methanosarcina, and Methanosaeta, had also been reported as the abundant group in the rice rhizosphere (Edwards et al. 2015). Methanosarcinaceae can utilize $\mathrm{H}_{2}$, methanol, methylamine, and acetate. Methanosaetaceae has been known as acetilastic methanogens. While Methanomassilliicoccaceae, Methanocellaceae, and Methanoregulaceae are hydrogenotrophic methanogens (Liu and Whitman 2008). Our study showed that Methanocella was only detected in B0, while a member of Methanoregulaceae was only found in B1 treatment (Figure 5). Methanocella (previously recognized as uncultured archaeal group rice cluster I (RC-I)) are considered to play a key role as methanogen in rice fields (Conrad et al. 2006). In contrast to this study, we found that ANME-2D (anaerobic methanotroph) was in low proportion, suggesting that this group plays a role in methane metabolism (Vaksmaa et al. 2017). Because of their low proportion, anaerobic oxidation of methane (AOM) might be a negligible metabolic process in rice ecosystems (Lee et al. 2014).

In conclusion, archaeal succession was observed in each of the two treatments throughout the rice-growing period. Crenarchaeota dominated the archaeal assemblage in the rice field soil under the two different fertilizer applications. Putative methanogens were more abundant in the application of $100 \%$ urea than that of the application of $50 \%$ urea with biofertilizer. Methanosarcinaceae and Methanomassiliicoccaceae were most commonly found in both treatments, and considered to play important roles in $\mathrm{CH}_{4}$ emission. The application of $50 \%$ urea with biofertilizer altered the archaeal and methanogenic community structure in the rice field, in comparison with the application of $100 \%$ urea.

\section{ACKNOWLEDGEMENTS}

The study was supported by the Directorate General of Higher Education, Republic of Indonesia, through the grants of the Master Program of Education Leading to Doctoral Degree for Excellent Graduate (PMDSU). 


\section{REFERENCES}

Ahn JH, Song J, Kim BY, Kim MS, Joa JH, Weon HY. 2012 Characterization of the bacterial and archaeal communities in rice field soils subjected to long-term fertilization practices. J Microbiol 50: 754-765.

Aulakh MS, Wassmann R, Bueno C, Rennenberg H. 2001a. Impact of root exudates of different cultivars and plant development stages of rice (Oryza sativa L.) on methane production in paddy soil. Plant Soil 230: 77-86.

Aulakh MS, Wassmann R, Bueno C, Rennenberg H. 2001b. Characterization of root exudates at different growth stages of ten rice (Oryza sativa L.) cultivars. Plant Biol 3: 139-148.

Bai R, Wang J-T, Deng Y, He J-Z, Feng K, Zhang L-M. 2017. Microbia community and functional structure significantly varied among distinct types of paddy soils but responded differently along gradients of soil depth layers. Front Microbiol 8: 1-16.

Biddle JF, Lipp JS, Lever MA, Lloyd KG, Sørensen KB, Anderson R, Fredricks HF, Elvert M, Kelly TJ, Schrag DP. 2006. Heterotrophic archaea dominate sedimentary subsurface ecosystems off Peru. PNAS 103: 3846-3851.

Bokulich NA, Subramanian S, Faith JJ, Gevers D, Gordon JI, Knight R, Mills DA, Caporaso JG. 2013. Quality-filtering vastly improves diversity estimates from Illumina amplicon sequencing. Nat Methods 10: $57-59$

Borrel G, O'Toole PW, Harris HMB, Peyret P, Brugère JF, Gribaldo S. 2013. Phylogenomic data support a seventh order of methylotrophic methanogens and provide insights into the evolution of methanogenesis. Genome Biol Evol 5: 1769-1780.

Borrel G, Parisot N, Harris HMN, Peyretaillade E, Gaci N, Tottey W, Bardot O, Raymann K, Gribaldo S, Peyret P, O'Toole PW, JeanFrançois Brugère JF. 2014. Comparative genomics highlights the unique biology of Methanomassiliicoccales, a Thermoplasmatalesrelated seventh order of methanogenic archaea that encodes pyrrolysine. BMC Genomic 15, 679. doi:10.1186/1471-2164-15-679.

Breidenbach B, Conrad R. 2015. Seasonal dynamics of bacterial and archaeal methanogenic communities in flooded rice fields and effect of drainage. Front Microbiol 5: 1-16.

Caporaso JG, et al. 2010. QIIME allows analysis of high-throughput community sequencing data. Nat Methods 7: 335-336.

Conrad R. 1996. Soil microorganisms as controllers of atmospheric trace gases $\left(\mathrm{H}_{2}, \mathrm{CO}, \mathrm{CH}_{4}, \mathrm{OCS}, \mathrm{N}_{2} \mathrm{O}\right.$, and NO). Microbiol Rev 60(4): 609. 640.

Conrad R, Erkel C, Liesack W. 2006. Rice cluster I methanogens, an important group of Archaea producing greenhouse gas in soil. Curr Opin Biotechnol 17: 262-267.

Conrad R. 2007. Microbial ecology of methanogens and methanotrophs. Adv Agron 96: 1-63.

Coolen MJL, Hopmans EC, Rijpstra WIC, Muyzer G, Schouten S, Volkman JK, Damste JSS. 2004. Evolution of the methane cycle in Ace Lake (Antarctica) during the Holocene: response of methanogens and methanotrophs to environmental change. Org Geochem 35: 11511167.

Delong EF. 1992. Archaea in coastal marine environments. PNAS 89: 5685-5689

DeSantis TZ, Hugenholtz P, Larsen N, Rojas M, Brodie EL, Keller K, Huber T, Dalevi D, Hu P, Andersen GL. 2006. Greengenes, a chimera-checked 16S rRNA gene database and workbench compatible with ARB. Appl Environ Microbiol 72: 5069-5072.

Edwards J, Johnson C, Santos-Medellína C, Luriea E, Podishetty NK, Bhatnagar S, Eisenc JA, Sundaresana V. 2015. Structure, variation, and assembly of the root-associated microbiomes of rice. PNAS: E911-E920.

Edgar RC, Haas BJ, Clemente JC, Quince C, Knight R. 2011. UCHIME improves sensitivity and speed of chimera detection. Bioinformatics 27: 2194-2200

Evans PN, Parks DH, Chadwick GL, Robbins SJ, Orphan VJ, Golding SD, Tyson GW. 2015. Methane metabolism in the archaeal phylum Bathyarchaeota revealed by genome-centric metagenomics. Science 350: 434-438.

Fan X, Xing P. 2016. Differences in the composition of archaeal communities in sediments from contrasting zones of Lake Taihu. Front Microbiol 7: 1-11
Fan X, Yu H, Wu Q, Ma J, Xu H, Yang J, Zhuang Y. 2016. Effects of fertilization on microbial abundance and emissions of greenhouse gases $\left(\mathrm{CH}_{4}\right.$ and $\left.\mathrm{N}_{2} \mathrm{O}\right)$ in rice paddy fields. Ecol Evol 6: 1054-1063.

Fatma YS. 2019. Effect of Methanotrophic and $\mathrm{N}_{2} \mathrm{O}$-Reducing Bacterial Application on $\mathrm{CH}_{4}$ and $\mathrm{N}_{2} \mathrm{O}$ Emissions, Paddy Growth, and Bacterial Community Structure in Paddy Field. [Thesis]. IPB University, Bogor. [Indonesian]

Fazli P, Man HC, Shah UKM, Idris A. 2013. Characteristics of methanogens and methanotrophs in rice fields: a review. Asia Pac J Mol Biol Biotechnol 21: 3-17.

Gründger F, Jiménez N, Thielemann T, Straaten N, Lüders T, Richnow HH, Krüger M. 2015. Microbial methane formation in deep aquifers of a coal-bearing sedimentary basin, Germany. Front Microbiol 6: 1-17.

IPCC (Intergovernmental Panel on Climate Change). 2007. Climate Change 2007: The Physical Science Basis. Contribution of Working Group I to the Fourth Assessment Report of the Intergovernmental Panel on Climate Change. Cambridge Univ Pr, Cambridge.

Itoh H, Ishii S, Shiratori Y, Oshima K, Otsuka S, Hattori M, Senoo K. 2013. Seasonal transition of active bacterial and archaeal communities in relation to water management in paddy soils. Microbes Environ 28: 370-380.

Lee HJ, Kim SY, Kim PJ, Madsen EL, Jeon CO. 2014. Methane emission and dynamics of methanotrophic and methanogenic communities in a flooded rice field ecosystem. FEMS Microbiol Ecol 88: 195-212.

Liu Y, Whitman WB. 2008. Metabolic, phylogenetic, and ecological diversity of the methanogenic archaea. Ann NY Acad Sci 1125: 171189.

Liu J, Zang H, Xu H, Zhang K, Jiang Y, Hu Y, Zeng Z. 2019. Methane emission and soil microbial communities in early rice paddy as influenced by urea-N fertilization. Plant Soil: 1-16.

Lloyd KG, Schreiber L, Petersen DG, Kjeldsen KU, Lever MA, Steen MA, Stepanauskas R, Richter M, Kleindienst S, Lenk S, Schramm A, Jørgensen BB. 2013. Predominant archaea in marine sediments degrade detrital proteins. Nature 496: 215-220.

Lueders T, Friedrich M. 2000. Archaeal population dynamics during sequential reduction processes in rice field soil. Appl Environ Microbiol 66: 2732-2742.

Magoč T, Salzberg SL. 2011. FLASH: fast length adjustment of short reads to improve genome assemblies. Bioinformatics 27: 2957-2963.

Mer JL, Roger P. 2001. Production, oxidation, emission and consumption of methane by soil: a review. Eur J Soil Biol 37: 25-50.

Nicol GW, Glover LA, Prosser JI. 2003. The impact of grassland management on archaeal community structure in upland pasture rhizosphere soil. Environ Microbiol 5: 152-162.

Reim A, Hernández M, Klose M, Chidthaisong A, Yuttitham M, Conrad $\mathrm{R}$ 2017. Response of methanogenic microbial communities to desiccation stress in flooded and rain-fed paddy soil from Thailand. Front Microbiol 8: 1-17.

Rusmana I, Akhdiya A. 2009. Isolation and characterization of methanotrophic bacteria from rice fields. Biotropia 16: 71-78.

Setyaningsih R, Rusmana I, Setyanto P, Suwanto A. 2010. Physiological characterization and molecular identification of denitrifying bacteria possesing nitrous oxide high reduction activity isolated from rice soils. Microbiol Indones 4: 75-78. [Indonesian]

Singh A, Singh RS, Upadhyay SN, Joshi CG, Tripathi AK, Dubey SK. 2012. Community structure of methanogenic archaea and methane production associated with compost-treated tropical ricefield soil. FEMS Microbiol Ecol 82: 118-134.

Sukmawati D, Rusmana I, Mubarik NR. 2015. The effectiveness of methanotrophic bacteria and Ochrobactrum anthropi to reduce $\mathrm{CH}_{4}$ and $\mathrm{N}_{2} \mathrm{O}$ emissions and to promote paddy growth in lowland paddy fields. Malays J Microbiol 12: 50-55.

Schűtz H, Seiler W, Conrad R. 1989. Processes involved in formation and emission of methane in rice paddies. Biogeochem 7: 33-35.

Trabelsi D, Mhamdi R. 2013. Microbial inoculants and their impact on soil microbial communities: A review. Biomed Res Int 2013: 1-11.

USEPA (United States Environmental Protection Agency). 2013. Global Mitigation of Non- $\mathrm{CO}_{2}$ Greenhouse Gases: 2010-2030. USEPA, Washington DC.

Vaksmaa A, van Alen TA, Ettwig KF, Lupotto E, Valè G, Jetten MSM, Lüke M. 2017. Stratification of diversity and activity of methanogenic and methanotrophic microorganisms in a nitrogen-fertilized italian paddy soil. Front Microbiol 8: 1-15.

Wang Q, Garrity GM, Tiedje JM, Cole JR. 2007. Naive bayesian classifier for rapid assignment of rRNA sequences into the new bacterial taxonomy. Appl Environ Microbiol 73: 5261-5267. 
Wang G, Watanabe T, Jin J, Liu X, Kimura M, Susumu A. 2010. Methanogenic archaeal communities in paddy field soils in north-east China as evaluated by PCR-DGGE, sequencing and real-time PCR analyses. Soil Sci Plant Nutr 56: 831-838.

Wang P, Wei Y, Li T, Li F, Meng J, Zhang CL. 2013. Archaeal diversity and spatial distribution in the surface sediment of the South China Sea. Geomicrobiol J 31: 1-11.

Watanabe T, Hosen Y, Agbisit R, Llorca L, Fujita D, Asakawa S, Kimura M. 2010. Changes in community structure and transcriptional activity of methanogenic archaea in a paddy field soil brought about by a water-saving management practice - estimation by PCR-DGGE and qPCR of $16 \mathrm{~S}$ rDNA and $16 \mathrm{Sr}$ RNA. Proceeding of $19^{\text {th }}$ World Congress of Soil Science, Soil Solutions for a Changing World. Brisbane, 1-6 August. [Australia]

Yuan J, Yuan Y, Xhu Y, Cao L. 2018. Effects of different fertilizers on methane emissions and methanogenic community structures in paddy rhizosphere soil. Sci Total Environ 627: 770-781. 